\title{
Significant Effects of CCR5delta32 Polymorphism on Alzheimer'S Disease, Neurological Disorders, Cancer, Diabetes and Viral Infection in the Worldwide Population
}

\author{
Orly Weissberg, Alessandro Gorohovski, Dorith Raviv Shay and Milana Frenkel-Morgenstern* \\ Cancer Genomics and BioComputing of Complex Diseases lab, The Azrieli Faculty of Medicine, Bar-Ilan University, Israel \\ *Corresponding author: Milana Frenkel-Morgenstern, Cancer Genomics and BioComputing of Complex Diseases lab, The Azrieli \\ Faculty of Medicine, Bar-Ilan University, Safed 13591, Israel. \\ To Cite This Article: Orly Weissberg, Alessandro Gorohovski, Dorith Raviv Shay and Milana Frenkel-Morgenstern. Significant Effects of \\ CCR5delta32 Polymorphism on Alzheimer'S Disease, Neurological Disorders, Cancer, Diabetes and Viral Infection in the Worldwide Population. \\ Am J Biomed Sci \& Res. 2021 - 13(2). AJBSR.MS.ID.001852. DOI: 10.34297/AJBSR.2021.13.001852.
}

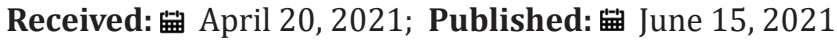

\begin{abstract}
The CCR5delta32 allele is a mutation in the sequence encoding CCR5 that leads to a loss of expression of this chemokine receptor, normally expressed on immune cells. The CCR5delta32 allele is known to provide protection against HIV and is involved in numerous diseases, including Alzheimer's disease. This study explored CCR5 involvement in different diseases by comparing CCR5delta32 allele frequency to the overall number of registered deaths attributed to Alzheimer's disease and neurological disorders, cancer, diabetes and viral infection in the worldwide population. Accordingly, we revealed significant positive correlations between CCR5delta32 allele frequency and Alzheimer's disease, numerous neurologic diseases and cancers but negative correlations between CCR5delta32 allele frequency and diabetes and viral infection. Our results thus highlight the differential involvement of the CCR5 receptor in various diseases and its importance as a potential therapeutic target. Moreover, this study emphasizes the importance of delineating the involvement of CCR5 in complex diseases and deciphering the mechanism of its actions.
\end{abstract}

\section{Introduction}

C-C chemokine receptor 5 (CCR5), a seven transmembrane G protein-coupled receptor (GPCRs), is a cell surface protein belonging to the $\beta$-chemokine receptor family that binds chemokines [1]. It is the natural receptor of the $\mathrm{C}$-C chemokine macrophage inflammatory proteins (MIP)-1 alpha (CCL3), MIP-1 beta (CCL4) and RANTES (regulated on activation, normal $\mathrm{T}$ cell expressed and secreted; CCL5) [2]. CCR5 is located on chromosome 3 and is presented on immune cells, as well as on microglia, astrocytes and neurons [3]. CCR5 mediates the transport of immune cells to inflammatory sites, including peripheral monocyte migration into the inflamed central nervous system, traversing the blood brain barrier (BBB) [4].

The CCR5delta32 allele is a 32 bp deletion in the CCR5 gene which results in the loss of a post-translational phosphorylation site. As a result, CCR5 biogenesis is prematurely terminated in the endoplasmic reticulum, such that the protein is not expressed on the cell surface [5]. Individuals carrying the CCR5delta32 allele were found to be less sensitive to HIV infection, with CCR5delta32 homozygosity having been shown to protect against HIV due to its role in cell penetration as a co-receptor [6]. Strong selective pressure is thought to have applied in favor of the CCR5delta32 allele [7]. Therefore, we hypothesized that this mutation might also play an important role in other viral infections. Accordingly, in late 2018, Jiankui He described genetically editing babies in whom CCR5 had been deleted for the purpose of protecting them from HIV infection [8]. In the present study, we examined the association between CCR5 and a variety of diseases, seeking to define the effects of CCR5 mutation from a broad perspective and highlight the implications of such mutation.

As CCR5 had been previously studied in the context of Alzheimer's disease (AD), with no clear conclusion been set, 
depending on the studied model [9], we analyzed the correlation between CCR5delta32 and $\mathrm{AD}$ and expanded this analysis to other neurological disorders. $\mathrm{AD}$ is a polygenic disease defined by the presence of amyloid plaques and neurofibrillary tangles (NFT) in neurons. Plaques are extracellular deposits of fibrils and amorphous aggregates of amyloid $\beta$-peptide (A $\beta)$, while NFTs are intracellular fibrillar aggregates of the microtubule-associated protein tau, which exhibits hyperphosphorylation and oxidative modifications [10]. Loss of memory and impairment of related cognitive functions are the main features of $\mathrm{AD}$, with neuronal damage eventually affecting basic bodily functions, leading to death [11]. Glial cells and neurons express CCR5 ligands, while CCR5 is up-regulated on reactive microglia associated with $A \beta$ deposits in $\mathrm{AD}$ patients [12]. CCR5 and its ligands can contribute to the recruitment of microglia to $A \beta$ deposits and are somehow involved in AD pathogenesis [4,12].

Various studies have suggested connections between AD and cancer $[13,14]$ and have also identified diabetes as a risk factor for developing AD [15]. Taking these considerations together, we decided to examine the relationship of CCR5delta32 and $\mathrm{AD}$ to cancer and diabetes. As such, we compared CCR5delta32 allele frequency to the percent of deaths resulting from various diseases and found positive Spearman correlation coefficients (SCC) between CCR5delta32 allele frequency and AD and many neurologic disorders and cancers. However, negative SCCs between CCR5delta32 allele frequency and $\mathrm{AD}$ and viral infection and diabetes were found. Our results thus highlight CCR5 being differently involved in various diseases, in turn, suggesting new research directions.

\section{Results}

We hypothesized that the CCR5delta32 allele is related to $\mathrm{AD}$ and they both are related to neurological disorders, cancer, diabetes and viral infection. As our data do not present normal distribution, we decided to perform SCC analysis to find correlations between the groups. When we explored differences in CCR5delta32 allele frequency relative to the percent of registered deaths from $\mathrm{AD}$ worldwide in 2017, we found positive correlation between CCR5delta32 allele frequency and AD ( $\mathrm{r}=0.4839$, p-value $<0.0001$; ) (Table $1 \&$ Figure 1). These results indicate that the presence of the CCR5delta32 allele is correlated with a high risk for AD and that CCR5 may be involved in resistance to AD.

Table 1: CCR5delta32 allele frequency and AD SCC correlation. Stars (“*”) represents a p-value 330 summary, with the higher the number of stars, the higher the correlation.

\begin{tabular}{|c|c|c|c|c|c|c|c|c|}
\hline \multirow[b]{2}{*}{ Disease } & \multicolumn{4}{|c|}{ CCR5 $(\Delta 32)$ Percent } & \multicolumn{4}{|c|}{ AD \& dementias } \\
\hline & SCC, $r$ & $\begin{array}{l}\mathrm{P} \text { (two- } \\
\text { tailed) }\end{array}$ & $\begin{array}{l}P \text { value } \\
\text { summary }\end{array}$ & $\begin{array}{c}\text { Significant } \\
(\text { alpha }=0.05)\end{array}$ & SCC, $r$ & $\begin{array}{l}P \text { (two- } \\
\text { tailed) }\end{array}$ & $\begin{array}{l}P \text { value } \\
\text { summary }\end{array}$ & $\begin{array}{c}\text { Significant } \\
(\text { alpha }=0.05)\end{array}$ \\
\hline CCR5 allele $(\Delta 32)$ percent & - & - & - & - & 0.4839 & $<0.0001$ & $* * * *$ & Yes \\
\hline \multicolumn{9}{|c|}{ Neurological disorders } \\
\hline $\mathrm{AD} \&$ dementias & 0.4839 & $<0.0001$ & $* * * *$ & Yes & - & - & - & - \\
\hline Epilepsy & -0.2984 & 0.0195 & $*$ & Yes & -0.138 & 0.289 & ns & No \\
\hline Mental disorders & 0.5693 & $<0.0001$ & $* * * *$ & Yes & 0.6184 & $<0.0001$ & $* * * *$ & Yes \\
\hline Motor neuron disease & 0.7098 & $<0.0001$ & $* * * *$ & Yes & 0.7095 & $<0.0001$ & $* * * *$ & Yes \\
\hline Multiple sclerosis & 0.7915 & $<0.0001$ & $* * * *$ & Yes & 0.4591 & 0.0002 & $* * *$ & Yes \\
\hline Neurological disorders & 0.7421 & $<0.0001$ & $* * * *$ & Yes & 0.8191 & $<0.0001$ & $* * * *$ & Yes \\
\hline Parkinson's disease & 0.7529 & $<0.0001$ & $* * * *$ & Yes & 0.737 & $<0.0001$ & $* * * *$ & Yes \\
\hline \multicolumn{9}{|c|}{ Cancer } \\
\hline All cancers & 0.7406 & $<0.0001$ & $* * * *$ & Yes & 0.6863 & $<0.0001$ & $* * * *$ & Yes \\
\hline Acute lymphoid leukemia & -0.2065 & 0.1104 & ns & No & 0.08604 & 0.5097 & ns & No \\
\hline \multicolumn{9}{|c|}{ Acute myeloid } \\
\hline leukemia & 0.7319 & $<0.0001$ & $* * * *$ & Yes & 0.5744 & $<0.0001$ & $* * * *$ & Yes \\
\hline Bladder cancer & 0.6323 & $<0.0001$ & $* * * *$ & Yes & 0.5304 & $<0.0001$ & $* * * *$ & Yes \\
\hline $\begin{array}{l}\text { Brain and nervous system } \\
\text { cancer }\end{array}$ & 0.5745 & $<0.0001$ & $* * * *$ & Yes & 0.4334 & 0.0005 & $* * *$ & Yes \\
\hline Breast cancer & 0.7063 & $<0.0001$ & $* * * *$ & Yes & 0.476 & 0.0001 & $* * *$ & Yes \\
\hline Cervical cancer & -0.2231 & 0.084 & ns & No & -0.3609 & 0.0043 & $* *$ & Yes \\
\hline Chronic lymphoid & 0.8534 & $<0.0001$ & $* * * *$ & Yes & 0.4667 & 0.0001 & $* * *$ & Yes \\
\hline \multicolumn{9}{|c|}{ leukemia } \\
\hline Chronic myeloid & 0.6181 & $<0.0001$ & $* * * *$ & Yes & 0.4304 & 0.0005 & $* * *$ & Yes \\
\hline
\end{tabular}




\begin{tabular}{|c|c|c|c|c|c|c|c|c|}
\hline \multicolumn{9}{|c|}{ leukemia } \\
\hline Colon and rectal & 0.7412 & $<0.0001$ & $* * * *$ & Yes & 0.5673 & $<0.0001$ & $* * * *$ & Yes \\
\hline \multicolumn{9}{|c|}{ cancer } \\
\hline Hodgkin lymphoma & -0.1393 & 0.2844 & ns & No & -0.257 & 0.0456 & $*$ & Yes \\
\hline Kidney cancer & 0.8365 & $<0.0001$ & $* * * *$ & Yes & 0.5851 & $<0.0001$ & $* * * *$ & Yes \\
\hline Larynx cancer & 0.0771 & 0.5548 & ns & No & -0.1508 & 0.2461 & ns & No \\
\hline Leukemia & 0.5569 & $<0.0001$ & $* * * *$ & Yes & 0.6935 & $<0.0001$ & $* * * *$ & Yes \\
\hline Lip and oral cavity cancer & 0.3995 & 0.0014 & $* *$ & Yes & 0.1153 & 0.3761 & ns & No \\
\hline Liver cancer & 0.1861 & 0.1511 & ns & No & 0.3447 & 0.0065 & $* *$ & Yes \\
\hline Malignant skin & 0.8247 & $<0.0001$ & $* * * *$ & Yes & 0.4908 & $<0.0001$ & $* * * *$ & Yes \\
\hline \multicolumn{9}{|c|}{ melanoma } \\
\hline Multiple myeloma & 0.7405 & $<0.0001$ & $* * * *$ & Yes & 0.7368 & $<0.0001$ & $* * * *$ & Yes \\
\hline Nasopharynx cancer & -0.06759 & 0.6048 & ns & No & 0.08969 & 0.4918 & ns & No \\
\hline Neoplasms & 0.7255 & $<0.0001$ & $* * * *$ & Yes & 0.6764 & $<0.0001$ & $* * * *$ & Yes \\
\hline Non-Hodgkin lymphoma & 0.5169 & $<0.0001$ & $* * * *$ & Yes & 0.6821 & $<0.0001$ & $* * * *$ & Yes \\
\hline Non-melanoma skin cancer & 0.5649 & $<0.0001$ & $* * * *$ & Yes & 0.4094 & 0.0011 & $* *$ & Yes \\
\hline Ovarian cancer & 0.781 & $<0.0001$ & $* * * *$ & Yes & 0.5318 & $<0.0001$ & $* * * *$ & Yes \\
\hline Pancreatic cancer & 0.7806 & $<0.0001$ & $* * * *$ & Yes & 0.6891 & $<0.0001$ & $* * * *$ & Yes \\
\hline Prostate cancer & 0.7824 & $<0.0001$ & $* * * *$ & Yes & 0.6341 & $<0.0001$ & $* * * *$ & Yes \\
\hline Stomach cancer & 0.3852 & 0.0022 & $* *$ & Yes & 0.5161 & $<0.0001$ & $* * * *$ & Yes \\
\hline Thyroid cancer & 0.2452 & 0.0568 & ns & No & 0.5439 & $<0.0001$ & $* * * *$ & Yes \\
\hline $\begin{array}{l}\text { Tracheal, bronchus, and lung } \\
\text { cancer }\end{array}$ & 0.6391 & $<0.0001$ & $* * * *$ & Yes & 0.5522 & $<0.0001$ & $* * * *$ & Yes \\
\hline Uterine cancer & 0.7006 & $<0.0001$ & $* * * *$ & Yes & 0.4147 & 0.0009 & $* * *$ & Yes \\
\hline \multicolumn{9}{|c|}{ Viral and bacrerial infections } \\
\hline Acute hepatitis A & -0.6438 & $<0.0001$ & $* * * *$ & Yes & -0.3634 & 0.004 & $* *$ & Yes \\
\hline Acute hepatitis B & -0.8055 & $<0.0001$ & $* * * *$ & Yes & -0.4302 & 0.0005 & $* * *$ & Yes \\
\hline Acute hepatitis C & -0.6705 & $<0.0001$ & $* * * *$ & Yes & -0.383 & 0.0023 & $* *$ & Yes \\
\hline Acute hepatitis E & -0.6036 & $<0.0001$ & $* * * *$ & Yes & -0.3412 & 0.0071 & $* *$ & Yes \\
\hline Bacterial skin & 0.07951 & 0.5424 & ns & No & 0.249 & 0.053 & ns & No \\
\hline \multicolumn{9}{|c|}{ diseases } \\
\hline HIV/AIDS & -0.4652 & 0.0002 & $* * *$ & Yes & -0.192 & 0.1382 & ns & No \\
\hline Leishmaniasis & -0.4743 & 0.0001 & $* * *$ & Yes & -0.338 & 0.0077 & $* *$ & Yes \\
\hline $\begin{array}{l}\text { Neglected tropical diseases } \\
\text { and malaria }\end{array}$ & -0.7854 & $<0.0001$ & $* * * *$ & Yes & -0.4443 & 0.0003 & $* * *$ & Yes \\
\hline Varicella and herpes zoster & -0.4261 & 0.0006 & $* * *$ & Yes & -0.1566 & 0.2282 & ns & No \\
\hline Diabetes mellitus type 1 & -0.6309 & $<0.0001$ & $* * * *$ & Yes & -0.6159 & $<0.0001$ & $* * * *$ & Yes \\
\hline Diabetes mellitus type 2 & -0.3122 & 0.0143 & $*$ & Yes & - & 0.8432 & ns & No \\
\hline
\end{tabular}

We next examined CCR5delta32 allele and AD involvement in other disorders affecting the nervous system. Accordingly, we found positive SCC correlations between CCR5delta32 allele frequency or $\mathrm{AD}$ and different mental disorders and motor neuron diseases, multiple sclerosis, certain neurological disorders, and Parkinson's disease. Surprisingly, we found negative SCC correlations between
CCR5delta32 allele frequency (but not AD) and epilepsy ( $\mathrm{r}=-0.2984$, p-value $<0.05$; (Table $1 \&$ Figure 1). These results indicate that CCR5 might contribute to preventing specific nervous system disorders and that these disorders might be a risk factor for AD. As such, we suggest further investigating these putative links. 


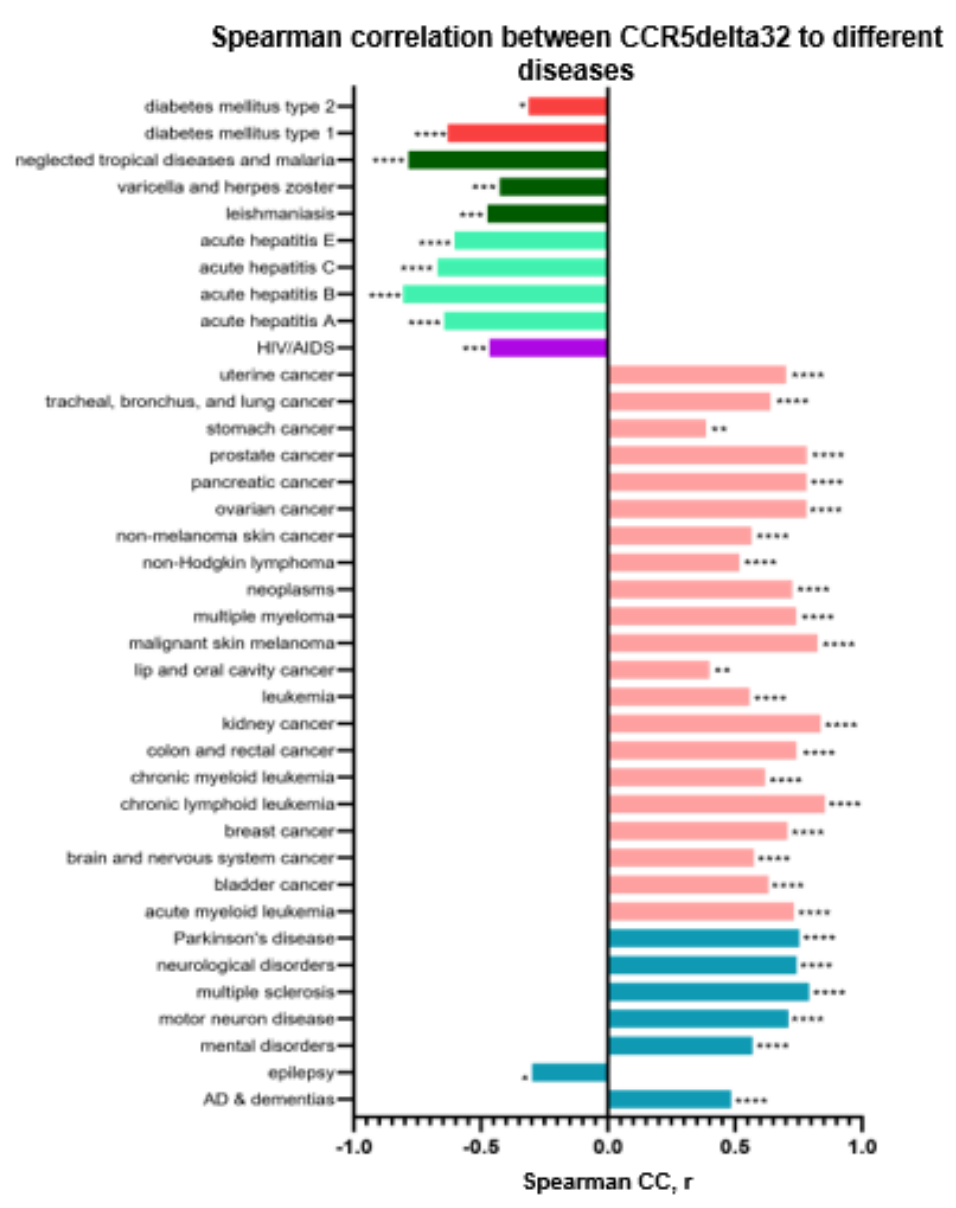

Figure 1: SCC correlations between CCR5delta 32 allele frequency and different diseases in the worldwide population. Significantly positive correlations were found between CCR5delta32 allele frequency and registered deaths from Alzheimer's disease and neurological disorders, different cancers, and rheumatoid arthritis. Negative correlations were found between CCR5delta32 allele frequency and registered deaths from epilepsy, HIV, diabetes, hepatitis, leishmaniasis, varicella and herpes zoster, and malaria.

Having proposed a link between CCR5delta32 allele frequency and $\mathrm{AD}$, we next addressed the relationship of CCR5delta32 allele frequency or $\mathrm{AD}$ and different cancers. We accordingly found positive SCC correlation with acute myeloid leukemia, bladder cancer, brain and nervous system cancers, breast cancer, chronic lymphoid and chronic myeloid leukemia, colon and rectal cancers, kidney cancer, leukemia, malignant skin melanoma, multiple myeloma, neoplasms, non-Hodgkin's lymphoma, non-melanoma skin cancer, ovarian cancer, pancreatic cancer, prostate cancer, stomach cancer, tracheal bronchus and lung cancers and uterine cancer. Positive SCCs were found between CCR5delta32 allele frequency and lip and oral cavity cancers, but not with $\mathrm{AD}$, and between $\mathrm{AD}$ and liver and thyroid cancers, but not with CCR5delta32. Negative SCC correlations were found between $\mathrm{AD}$ and cervical cancer and Hodgkin's lymphoma (Table 1 \& Figure 1). According to these results, CCR5 might act as a protective agent in many cancers that may be suspected as risk factors for AD.

Having established a relationship between CCR5delta32 allele frequency with $\mathrm{AD}$ and considering studies linking $\mathrm{AD}$ and diabetes on the basis of shared molecular and cellular features [16], we checked for an $\mathrm{AD}$ and CCR5delta32 allele relationship with diabetes by SCC. We found negative SCC correlations between CCR5delta32 allele frequency and diabetes mellitus types 1 and 2 but negative correlation only for $\mathrm{AD}$ and diabetes mellitus type 1 (Table 1 \& Figure 2). We thus concluded that diabetes mellitus type 1 is not likely to be a risk factor for AD and suggest that CCR5 serves a possible role in protection against diabetes.

Comparing CCR5delta32 allele frequency with viral infection, we found negative SCC correlation between CCR5delta32 allele frequency or $\mathrm{AD}$ and acute hepatitis $\mathrm{A}, \mathrm{B}, \mathrm{C}$, and $\mathrm{E}$, leishmaniasis, neglected tropical diseases, malaria and between CCR5delta32 allele frequency and HIV/AIDS and varicella and herpes zoster (Table 1 \& Figure 1). It can thus be assumed that many viral infections present inverse relationships with CCR5delta32 allele frequency. Hence, people presenting the CCR5delta32 allele would be expected to have some immune resistance to these diseases, as in the case of HIV. This also implies that some viruses might offer a protective effect against AD. 


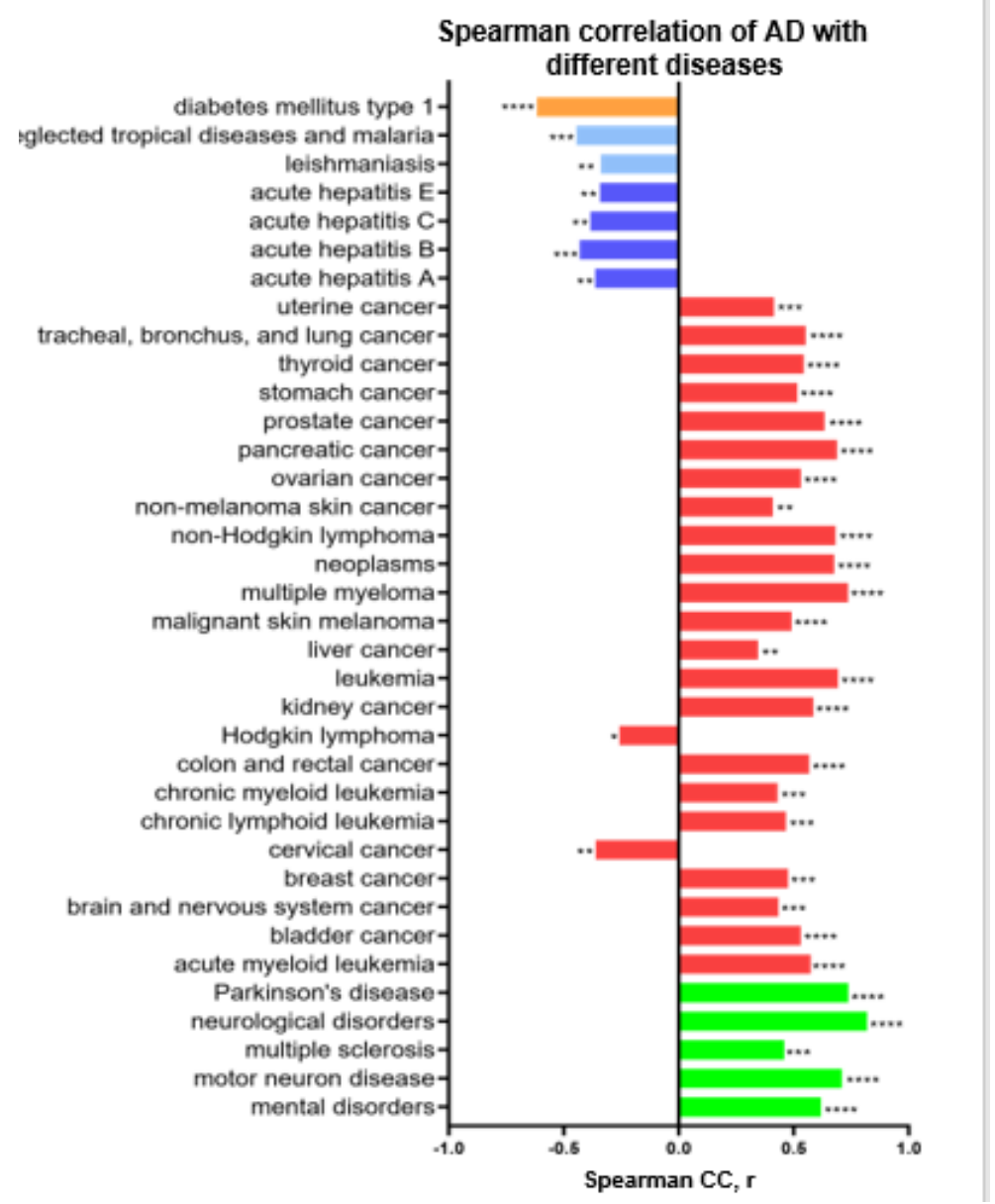

Figure 2: SCC correlations between Alzheimer's disease and other diseases in the worldwide population. Significantly positive correlations were found between registered deaths from Alzheimer's disease and neurological disorders, different cancers, and rheumatoid arthritis. Negative correlations were found between registered deaths from Alzheimer's disease and registered death cases from Hodgkin's lymphoma, cervical cancer, diabetes type 1, hepatitis, leishmaniasis, and malaria.

\section{Discussion}

\section{The role of CCR5 in AD and other neurological disorders}

In this project, we considered the involvement of CCR5 gene deletion in the form of CCR5delta32 allele frequency in various diseases by exploring the spread of this deletion among 61 countries versus the percent of recorded deaths attributed to different diseases in the same locations. Results were analysed using SCC and revealed positive correlation between CCR5delta32 allele frequency and $\mathrm{AD}$. We expanded our analysis to various disorders related to the nervous system and found positively correlations with CCR5delta32 allele frequency and AD.

The numerous studies that have tried to link CCR5delta32 to $\operatorname{AD}[9,17,18]$ included small cohorts of patients and focused solely on subjects from a single country. As far as we know, the current study is the first worldwide analysis addressing this link. Brain inflammation is a pathological hallmark of AD. For decades, it was accepted that $\mathrm{AD}$ is the outcome of losing immune system balance, such that blocking immune responses was seen as a route to treat $\mathrm{AD}[19,20]$. In contrast, others claimed that the immune system protein CCR5 improves memory in AD patients. The Schwartz group was one of the first to propose that the immune system can combat AD [21]. Over time, support for this concept has accumulated. Growing evidence also links neuroinflammation with $\mathrm{AD}$, with emphasis on the role of CCR5 in this process [22]. Chronic activation of an inflammatory feedback loop by amyloid plaques and neurofibrillary tangles induces the expression and release of proinflammatory cytokines by activated microglial cells that are found in amyloid plaques during the early and late phases of $\mathrm{AD}$ [23]. It has been shown that chemokines and their receptors, particularly CCR5, are involved in recruiting microglia and monocytes into the brain and activate these cells to uptake amyloid beta [24]. Amyloid beta plaques stimulate activation of microglial and glial cells that induce the production of pro-inflammatory cytokines and chemokines [25-27]. Chemokines and their receptors were found to be upregulated in AD brain cells. Increased CCR5 
and CCL5 levels in the brain of a mouse AD model were also found [28]. In vitro studies have demonstrated the ability of amyloid beta to stimulate production of the CCR5 ligands CCL3 and CCL4. Furthermore, in reactive astrocytes, CCL3 was detected in nearby sites of plaque-associated inflammation and neurodegeneration $[29,30]$. Hwang et al. reported that CCR5 knockout mice produced amyloid beta deposits and showed impaired memory function, in contrast to wild type mice [31]. Other studies have shown that amyloid beta up-regulates CCR5 expression, leading to $\mathrm{T}$ cell infiltration of the brain via the BBB [32]. CCR5 also chemotactically attracts microglia to the brain [33]. Keren-Shaul et al. found upregulation of unique microglial cells in mouse AD brain [34]. At the same time, consideration of the immune system as a therapeutic target for treating neurodegenerative diseases other than $\mathrm{AD}$ is lacking. In these disorders, the immune system can also be considered to be part of the problem and not part of the solution. Still, Wojta et al. recently detected CCR5delta32 carriers in early age of onset neurodegenerative disease patients [35]. Choi et al. found that CCR5 might be important for dopaminergic neuron survival in Parkinson's disease [36].

The multiple sclerosis disability status scale score is significantly expanded in CCR5delta32-presenting individuals [37]. Our results highlight CCR5 involvement in AD and other neurological disorders and support the importance of the immune system for therapy, with emphasis on the contribution of CCR5 in fighting AD and additional neurological disorders.

Surprisingly, whereas most neurological disorders show positive correlation with $\mathrm{AD}$ and CCR5delta32 allele frequency, negative CCR5delta32 allele correlation was found with epilepsy (no significant correlation was found for AD with epilepsy). In studies on epilepsy using rat models, blocking CCR5 function led to protection from seizures, neuroinflammation, BBB damage, and neuron loss [38]. However, none of the studies specifically examined CCR5 involvement in the disease. As such, we suggest examining CCR5 inhibition as epilepsy therapy.

\section{CCR5, AD and cancer}

It has been previously suggested that negative correlation exists between patients with $\mathrm{AD}$ and those with cancer. The inverse pathway of these two diseases, namely that cancer is mostly identified with proliferation while $\mathrm{AD}$ involves degeneration $[13,39,40]$, supports this relation. Therefore, we sought correlation between $\mathrm{AD}$ or presence of the CCR5delta32 allele and different cancers (Figure $1 \& 2$ ). While numerous such positive correlations were detected, no significant correlation of AD or the CCR5delta32 allele and acute lymphoid leukemia, larynx cancer, nasopharynx cancer, or between the CCR5delta32 allele and liver cancer, Hodgkin's lymphoma, thyroid cancer, and cervical cancer were seen. Indeed, we only found negative correlation between $\mathrm{AD}$ and cervical cancer and Hodgkin's lymphoma. According to these results, it can be assumed that $\mathrm{AD}$ and most cancers have direct connection (Figure $1 \& 2$ ).

In cancer, as well as in $\mathrm{AD}$, the conventional therapeutic approach advocates the use of CCR5 blockers [41,42]. As early as 1986, Dvorak compared the wound-healing process and cancer, claiming that immune system cells are present in the tumor and can be recruited for its elimination [43]. Correlation between the CCR5delta32 allele and breast cancer was also previously suspected, although no significance was found, perhaps due to the low number of research cohorts considered [44]. Our detailed analysis, however, found that despite the different pathways involved, cancers and neurodegenerative diseases share common factors, as previously reported $[45,46]$. For instance, it was shown that amyloid precursor protein (APP) is over-expressed in breast cancer and other cancers, is related to tumorigenicity [47] and its expression is associated with neurodegenerative diseases and cancer $[48,49]$. In addition, APP cleavage via the non-amyloidogenic APP pathway is related to a series of malignancies [50,51]. A GWAS study revealed positive correlation between $\mathrm{AD}$ and colon, breast, prostate, ovarian, and lung cancers, indicative of shared genetic variants [52].

The therapeutic strategy of CCR5 inhibition as tumor therapy in colon cancer did not, however, show success [53]. Recently, Okereke and Meadows [54] indicated flaws in studies of the relationship between $\mathrm{AD}$ and cancer. In our opinion, this is relevant for most studies indicating an inverse relationship between $\mathrm{AD}$ and other neurodegenerative diseases and cancer. One of the most significant problems in such efforts is the breadth of research data and its geographical spread, reflective of the complexity in collecting big and heterogeneous data for research. Another challenge to such studies involves extrapolation to different cancers and most importantly, the inability to define treatments. According to our results, there is direct relationship between most neurodegenerative diseases and the majority of cancers, such that cancer treatment may have therapeutic effects on neurodegenerative disorders in parallel.

While there is support for the concept of a relationship between the immune system and cancer, the mechanisms involved remain unclear [55]. Inflammatory responses play important roles at different stages of cancer and can affect immune surveillance and response to therapy [56]. One of the mechanisms tumors use to avoid immune system recognition and elimination involves cytokine production that inhibits normal pathways of the immune response [57]. During the first stage of tumor development, immunogenic cancer cells are eliminated by T cells [58]. Recently, Crowther et al. reported that a unique $\mathrm{T}$ cell lineage recognizes the MHC-Irelated protein MR1 on cancer cells and kills such cells via a T cell receptor-mediated mechanism [59]. These T cells were found to identify a wide range of cancer cell types, including primary cancer 
cells. We assume that as CCR5 recruits T cells to inflammatory sites, the CCR5delta32 allele would prevent such recruitment, thereby enabling tumor proliferation.

\section{CCR5, AD and viral infection}

We also examined the relationship of AD and CCR5delta32 allele frequency with viral infection. We found negative correlation with acute hepatitis A, acute hepatitis B, acute hepatitis C, acute hepatitis $\mathrm{E}$, leishmaniasis and other neglected tropical diseases, and malaria. In addition, we noted negative correlation between CCR5delta32 allele frequency (but no significant correlation for AD) and HIV/ AIDS, varicella and herpes zoster (Figure $1 \& 2$ ). It is well known that the CCR5delta32 allele provides protection against HIV [60] due to the role of CCR5 in HIV entry into cells [61]. The CCR5CCL5 axis is known to be important in the context of hepatitis, with the CCR5delta32 allele having been found to have a protective effect against hepatitis B $[62,63]$. Later, it was found that hepatitis $\mathrm{C}$ virus replication can be inhibited by blocking CCR5 [64]. CCR5 has also been tied to varicella and herpes zoster infection $[65,66]$, leishmaniasis [67] and malaria [68]. As these findings support the concept of the CCR5delta32 allele providing a protective effect against viral infection, we suggest examining CCR5 inhibition as therapy for different viral infections, in addition to HIV.

\section{CCR5, AD and diabetes}

Several studies have identified diabetes as an AD risk factor [15]. Given the relationship of the CCR5delta32 allele with $\mathrm{AD}$, we examined the relation of $\mathrm{AD}$ and the CCR5delta32 allele with diabetes. We found negative SCC correlation between CCR5delta32 allele frequency and diabetes mellitus types 1 and 2 but significant negative correlation only between $\mathrm{AD}$ and diabetes mellitus type 1 (Figure $1 \& 2$ ). Diabetes type 2 has significantly lower prevalence rates in Europe, relative to the rest of the world [69]. CCR5 and its ligand CCL5 were found to be up-regulated in diabetes type 2 patients [70]. It was, moreover, found that the CCR5delta32 allele has a protective effect against type 1 diabetes [71]. CCR5 inhibition in non-obese mice inhibited beta cell destruction and diabetes [72]. In humans carrying the CCR5delta32 allele, the age of diabetes type 1 onset was delayed and morbidity due to diabetes type 2 was reduced [73]. In Australian and New Zealand populations, partial protection from diabetes type 1 was observed in individuals homozygous for the CCR5delta32 allele [74]. At the same time, CCR5 down-regulation in cell cultures promoted a protective mechanism against cellular destruction in diabetes type 1 [75]. In diabetes type 2 , the CCR5delta32 allele is associated with better survival and a protective effect [76]. Diabetes is associated with viruses, such as hepatitis B and C $[25,77]$,

Epstein-Barr virus, human papillomavirus, cytomegalovirus, and herpes simplex virus type 1 [78]. While studies have indicated impaired cognitive performance in diabetics with or without insulin-dependence, post-mortem diabetic brains showed no evidence of AD pathology, implying that diabetes is not a risk factor for AD. Our study revealed that CCR5 might play an important role in diabetes pathogenesis and that diabetes may be a disease associated with viral infection, as CCR5 correlates these two in the same manner.

\section{CCR5 is involved in various diseases in different manners}

The pioneering aspect of the present study was its analysis of large data cohorts comparing CCR5delta32 allele frequency to $\mathrm{AD}$ and other neurodegenerative disorders, different cancers, viral diseases and diabetes across the global population. Our results indicate positive correlation of CCR5 and AD and other neurodegenerative disorders and cancers but show an inverse relationship with viral infection and diabetes. We, therefore, suggest using CCR5 inhibition to treat viral infection, as well as diabetes, yet propose recruiting CCR5 to fight $\mathrm{AD}$, neurologic disorders and various cancers. Our data are thus relevant in the context of the impact of CCR5 and immune system activity in these diseases and could open new research directions for treatment options.

\section{Methods}

2017 data for CCR5delta32 allele frequency in different countries were taken from Solloch et al. Data for deaths due to different diseases in different countries in 2017 were obtained from the Global Health Data Exchange (GHDx) (http://ghdx. healthdata.org/). Using the GBD Results Tool, worldwide locations were chosen according to CCR5delta32 allele frequency. Context cause was selected for all ages and both sexes, using percent as the metric. Deaths were tabulated according to measure and cause for the diseases listed below. Analysis was performed and graphs were drawn using GraphPad Prism 8, version

Data for the following diseases were compared: Alzheimer's disease and dementia, neurological disorders, motor neuron disease, epilepsy, mental disorders, Parkinson's disease, multiple sclerosis, HIV/AIDS, breast cancer, brain and nervous system cancer, acute lymphoid leukemia, acute myeloid leukemia, chronic lymphoid leukemia, chronic myeloid leukemia, colon and rectal cancer, bladder cancer, kidney cancer, larynx cancer, leukemia, lip and oral cavity cancer, liver cancer, malignant skin melanoma, nasopharynx cancer, Hodgkin's and non-Hodgkin's lymphoma, non-melanoma skin cancer, uterine cancer, tracheal, bronchus, and lung cancer, thyroid cancer, stomach cancer, ovarian cancer, prostate cancer, multiple myeloma, other leukemia, pancreatic cancer, cervical cancer, neoplasms, acute hepatitis A, acute hepatitis B, acute hepatitis C, acute hepatitis E, diabetes mellitus type 1, diabetes mellitus type 2, bacterial skin diseases, leishmaniasis, neglected tropical diseases and malaria, varicella and herpes zoster. 
Data from the following countries were compared: Albania, Algeria, Austria, Azerbaijan, Bangladesh, Belgium, Bosnia and Herzegovina, Brazil, Cameroon, Canada, Colombia, Congo, Croatia, Cuba, Czech Republic, Denmark, Dominican Republic, Ecuador, Egypt, El Salvador, Eritrea, Estonia, Finland, France, Georgia, Germany, Ghana,

Greece, India, Indonesia, Iran, Iraq, Ireland, Israel, Italy, Japan, Jordan, Kenya, Lebanon, Luxembourg, Macedonia, Mexico, Morocco, Netherlands, Nigeria, Norway, Pakistan, Peru, Philippines, Portugal, Serbia, Slovakia, Slovenia, Somalia, South Korea, Spain, Sri Lanka, Switzerland, Tunisia, Turkey, United Kingdom.

\section{Competing Interests}

The authors must declare that there are any competing interests in relation to the work described.

\section{References}

1. McNicholl JM, Smith DK, Qari SH, Hodge T (1997) Host genes and HIV: the role of the chemokine receptor gene CCR5 and its allele. Emerg Infect Dis 3(3): 261-271.

2. Wu L, LaRosa G, Kassam N, Gordon CJ, Heath H, et al. (1997) Interaction of chemokine receptor CCR5 with its ligands: Multiple domains for HIV1 gp120 binding and a single domain for chemokine binding. J Exp Med 186(8): 1373-1381.

3. Sorce S, Myburgh R, Krause K (2011) The chemokine receptor CCR5 in the central nervous system. Prog Neurobiol 93(2): 297-311.

4. Giunti D, Borsellino G, Benelli R, Marchese M, Capello E, et al. (2003) Phenotypic and functional analysis of $\mathrm{T}$ cells homing into the CSF of subjects with inflammatory diseases of the CNS Abstract: The recruitment of lymphocytes across the blood brain barrier ( BBB ) is mediated by ad- healthy subject, similarly migrated to. J Leukoc Biol 73(5): 584-590.

5. Benkirane M, Jin DY, Chun RF, Koup RA, Jeang KT (1997) Mechanism of transdominant inhibition of CCR5-mediated HIV-1 infection by ccr $5 \Delta 32$. J Biol Chem 272(49): 30603-30606.

6. Sullivan AD, Wigginton J, Kirschner D (2001) The coreceptor mutation CCR5 $\triangle 32$ influences the dynamics of HIV epidemics and is selected for by HIV 98(18): $10214-10219$.

7. Zajac V (2018) Evolutionary view of the AIDS process. J Int Med Res 46(10): 4032-4038.

8. Xu M (2020) CCR5- $\Delta 32$ biology, gene editing, and warnings for the future of CRISPR-Cas9 as a human and humane gene editing tool. Cell Biosci 10(1): 1-6.

9. Balistreri CR, Grimaldi MP, Vasto S, Listi F, Chiappelli M, et al. (2006) Association between the polymorphism of CCR5 and Alzheimer's disease: Results of a study performed on male and female patients from northern Italy. Ann N Y Acad Sci. 1089: 454-461.

10. Mattson MP (2004) Pathways Towards and Away from Alzheimer's Disease NIH Public Access. Nature 430(7000): 631-639.

11. Huang Y, Mucke L (2012) Alzheimer mechanisms and therapeutic strategies. Cell 148(6): 1204-1222.

12. Xia M, Qin S, Wu L, Mackay CR, Hyman BT (1998) Immunohistochemical study of the $\beta$ chemokine receptors CCR3 and CCR5 and their ligands in normal and Alzheimer's disease brains. Am J Pathol 153(1): 31-37.
13. Shafi O (2016) Inverse relationship between Alzheimer's disease and cancer, and other factors contributing to Alzheimer's disease: A systematic review. BMC Neurol 16(1): 1-17.

14. Nixon DW (2017) The Inverse Relationship Between Cancer and Alzheimer's Disease: A Possible Mechanism. Curr Alzheimer Res 14(8): 883-893.

15. Kandimalla R, Thirumala V, Reddy PH, Biophys B, Author A (2017) Is Alzheimer's disease a Type 3 Diabetes? A Critical Appraisal Graphical Abstract HHS Public Access Author manuscript. Biochim Biophys Acta 1863(5): 1078-1089.

16. Khorram Khorshid HR, Manoochehri M, Nasehi L, Ohadi M, Rahgozar M, et al. (2012) Ccr264i and Ccr5 $\Delta 32$ Polymorphisms in Patients with Late-Onset Alzheimer's disease; A Study from Iran (Ccr2-64i And Ccr5 $\Delta 32$ Polymorphisms in Alzheimer's disease). Iran J Basic Med Sci 15(4): 937-944.

17. Combarros O, Infante J, Llorca J, Peña N, Fernández-Viadero C, et al. (2004) The chemokine receptor CCR5- $\triangle 32$ gene mutation is not protective against Alzheimer's disease. Neurosci Lett 366(3): 312-314.

18. Passos GF, Figueiredo CP, Prediger RDS, Pandolfo P, Duarte FS, et al. (2009) Role of the Macrophage Inflammatory Protein-1 $\alpha /$ CC Chemokine Receptor 5 Signaling Pathway in the Neuroinflammatory Response and Cognitive Deficits Induced by $\beta$-Amyloid Peptide. Am J Pathol 175(4): 1586-1597.

19. Goldeck D, Larbi A, Pellicanó M, Alam I, Zerr I, et al. (2013) Enhanced Chemokine Receptor Expression on Leukocytes of Patients with Alzheimer's Disease. PLoS One.

20. Schwartz M, Peralta Ramos JM, Ben-Yehuda H (2020) A 20-Year Journey from Axonal Injury to Neurodegenerative Diseases and the Prospect of Immunotherapy for Combating Alzheimer's Disease. J Immunol 204(2): 243-250.

21. Serpente M, Bonsi R, Scarpini E, Galimberti D (2014) Innate Immune System and Inflammation in Alzheimer's Disease: From Pathogenesis to Treatment. Neuroimmunomodulation 21(2-3): 79-87.

22. Nudelman KNH, McDonald BC, Lahiri DK, Saykin AJ (2019) Biological Hallmarks of Cancer in Alzheimer's Disease. Mol Neurobiol 56(10): 7173-7187.

23. Guedes JR, Lao T, Cardoso AL, El Khoury J (2018) Roles of microglial and monocyte chemokines and their receptors in regulating Alzheimer's disease-associated amyloid-\$ $\beta \$$ and tau pathologies. Front Neurol 9: 549 .

24. Desbois AC, Cacoub P (2017) Diabetes mellitus, insulin resistance and hepatitis $C$ virus infection: A contemporary review. Vol. 23, World Journal of Gastroenterology. Baishideng Publishing Group Co Limited 23(9): 1697-1711.

25. Robert R, Wark KL (2012) Engineered antibody approaches for Alzheimer's disease immunotherapy. Arch Biochem Biophys 526(2): 132-138.

26. Atwood CS, Obrenovich ME, Liu T, Chan H, Perry G, et al. (2003) Amyloid- $\beta$ : a chameleon walking in two worlds: a review of the trophic and toxic properties of amyloid- $\beta$ 43(1): 1-16.

27. López-González I, Schlüter A, Aso E, Garcia-Esparcia P, Ansoleaga B, et al. (2015)Neuroinflammatory signals in alzheimer disease and APP/ PS1 transgenic mice: Correlations with plaques, tangles, and oligomeric species. J Neuropathol Exp Neurol. 74(4): 319-344.

28. Hwang CJ, Park MH, Hwang JY, Kim JH, Yun NY, et al. (2016) CCR5 Deficiency Accelerates Astrogliosis , Amyloid-Beta Deposit and Impaired Memory Function. Oncotarget 7(11): 11984-11999.

29. Li M, Shang DS, Zhao WD, Tian L, Li B, et al. (2009) Amyloid Interaction with Receptor for Advanced Glycation End Products Up-Regulates Brain 
Endothelial CCR5 Expression and Promotes T Cells Crossing the BloodBrain Barrier. J Immunol 182(9): 5778-5788.

30. Rosi S, Pert CB, Ruff MR (2005) Chemokine Receptor 5 Antagonist D -AlaPeptide T-Amide Reduces Microglia And Astrocyte Activation Within The Hippocampus In A Neuroinflammatory Rat Model Of Alzheimer ' S Disease 134: 671-676.

31. Keren-Shaul H, Spinrad A, Weiner A, Matcovitch-Natan O, Dvir-Szternfeld R, et al. (2017) A Unique Microglia Type Associated with Restricting Development of Alzheimer's Disease. Cell 169(7): 1276-1290.

32. Wojta KJ, Ayer AH, Ramos EM, Nguyen PD, Karydas AM, et al. (2020) Lack of Association between the CCR5 -delta32 Polymorphism and Neurodegenerative Disorders. Alzheimer Dis Assoc Disord.

33. Choi DY, Lee MK, Hong JT (2013) Lack of CCR5 modifies glial phenotypes and population of the nigral dopaminergic neurons, but not MPTPinduced dopaminergic neurodegeneration. Neurobiol Dis 49(1): 159 168.

34. D’Angelo R, Crisafulli C, Rinaldi C, Ruggeri A, Amato A, et al. (2011) CCR5 432 Polymorphism Associated with a Slower Rate Disease Progression in a Cohort of RR-MS Sicilian Patients. Mult Scler Int p. 1-6.

35. Louboutin J, Chekmasova A, Marusich E, Agrawal L, Strayer DS (2011) Role of CCR5 and its ligands in the control of vascular inflammation and leukocyte recruitment required for acute excitotoxic seizure induction and neural damage. FASEB J. 25(2): 737-753.

36. Behrens M, Lendon C, Roe C (2009) A Common Biological Mechanism in Cancer and Alzheimers Disease? Curr Alzheimer Res. 6(3): 196-204.

37. Realmuto S, Cinturino A, Arnao V, Mazzola MA, Cupidi C, et al. (2012) Tumor diagnosis preceding alzheimer's disease onset: Is there a link between cancer and alzheimer's disease? J Alzheimer's Dis 31(1): 177182.

38. Kranjc MK, Novak M, Pestell RG, Lah TT (2019) Cytokine CCL5 and receptor CCR5 axis in glioblastoma multiforme. Radiol Oncol 53(4): 397-406.

39. Karin N, Razon H (2018) The role of CCR5 in directing the mobilization and biological function of $\mathrm{CD} 11 \mathrm{~b}+\mathrm{Gr} 1+$ Ly6Clow polymorphonuclear myeloid cells in cancer. Cancer Immunol Immunother 67(12): 1949 1953.

40. Dvorak HF (1986) Tumors: wounds that do not heal. Similarities between tumor stroma generation and wound healing. N Engl J Med 315(26): 1650-1659.

41. Li J, Peng Y, Liu H, Wu Q (2017) The association between CCR5 $\Delta 32$ polymorphism and susceptibility to breast cancer. Oncotarget $8(47)$ : 82796-82802.

42. Chen Y, Xu C, Harirforoosh S, Luo X, Wang KS, et al. (2018) Analysis of PTPRK polymorphisms in association with risk and age at onset of Alzheimer's disease, cancer risk, and cholesterol HHS Public Access. J Psychiatr Res 96: 65-72.

43. Harrington C, Song Z, Zhang T, Han Y, Wang J, et al. Comparative Epidemiological Investigation of Alzheimer's Disease and Colorectal Cancer: The Possible Role of Gastrointestinal Conditions in the Pathogenesis of AD. HYPOTHESIS AND THEORY 10: 176

44. Lim S, Yoo K, Kim H-S, Gilmore HL, Lee Y, et al. (2014) Amyloid- $\beta$ precursor protein promotes cell proliferation and motility of advanced breast cancer.

45. Staropoli JF (2008) Tumorigenesis and neurodegeneration: Two sides of the same coin? BioEssays 30(8): 719-727.

46. Sun W, Vanhooke JL, Sondek J, Zhang Q (2011) High-throughput fluorescence polarization assay for the enzymatic activity of gtpaseactivating protein of ADP-ribosylation factor (ARFGAP). J Biomol Screen 16(7): 717-723.
47. Galvão F, Grokoski KC, da Silva BB, Lamers ML, Siqueira IR (2019) The amyloid precursor protein (APP) processing as a biological link between Alzheimer's disease and cancer. Ageing Res Rev 49: 83-91.

48. Feng Y-CA, Cho K, Lindstrom S, Kraft P, Cormack J, et al. (2017) Investigating the genetic relationship between Alzheimer's disease and cancer using GWAS summary statistics HHS Public Access. Hum Genet 136(10): 1341-1351.

49. Ward ST, Li KK, Hepburn E, Weston CJ, Curbishley SM, et al. (2015) The effects of CCR5 inhibition on regulatory T-cell recruitment to colorectal cancer. Br J Cancer 112(2): 319-328.

50. Okereke OI, Meadows ME (2019) More Evidence of an Inverse Association Between Cancer and Alzheimer Disease. JAMA Netw Open 2(6): e196167.

51. Coussens LM, Werb Z (2002) Inflammation and cancer. Nature 420(6917): 860-867

52. Grivennikov SI, Greten FR, Karin M (2010) Immunity, inflammation, and cancer. Cell 140(6): 883-899.

53. Pardoll DM (2002) Spinning molecular immunology into successful immunotherapy. Nat Rev Immunol 2(4): 227-238.

54. Gonzalez H, Hagerling C, Werb Z (2018) Roles of the immune system in cancer: From tumor initiation to metastatic progression. Genes Dev 32(19-20): 1267-1284.

55. Crowther MD, Dolton G, Legut M, Caillaud ME, Lloyd A, et al. (2020) Genome-wide CRISPR-Cas9 screening reveals ubiquitous T cell cancer targeting via the monomorphic MHC class I-related protein MR1. Nat Immunol 21(2): 178-185.

56. Olivier IS, Naidoo V (2018) Risk Factors and Pathogenesis of HIVAssociated Neurocognitive Disorder: The Role of Host Genetics. Int J Mol Sci 19(11):3594.

57. Basova L, Najera JA, Bortell N, Wang D, Moya R, et al. (2018) Dopamine and its receptors play a role in the modulation of CCR5 expression in innate immune cells following exposure to Methamphetamine: Implications to HIV infection. PLoS One 13(6): 1-23.

58. Abdolmohammadi R, Azar SS, Khosravi A, Shahbazi M (2016) CCR5 polymorphism as a protective factor for hepatocellular carcinoma in hepatitis B virus-infected Iranian patients. Asian Pacific J Cancer Prev 17(10): 4643-4646.

59. Ganczak M, Skonieczna Zydecka K, Drozd-D, Abrowska M, Zyna Adler G (2017) Possible Impact of 190G > A CCR2 and $\Delta 32$ CCR5 Mutations on Decrease of the HBV Vaccine Immunogenicity-A Preliminary Report.

60. Blackard JT, Kong L, Rouster SD, Karns R, Horn PS, et al. (2019) CCR5 receptor antagonism inhibits hepatitis $\mathrm{C}$ virus (HCV) replication in vitro. PLoS One 14(10): 1-11.

61. Marsden V, Donaghy H, Bertram KM, Harman AN, Nasr N, et al. (2015) Herpes Simplex Virus Type 2-Infected Dendritic Cells Produce TNF- $\alpha$ Which Enhances CCR5 Expression and Stimulates HIV Production from Adjacent Infected Cells. J Immunol 194(9): 4438-4445.

62. Almanzar G, Kienle F, Schmalzing M, Maas A, Tony HP, et al. (2019) Tofacitinib modulates the VZV-specific CD4+ T cell immune response in vitro in lymphocytes of patients with rheumatoid arthritis. Rheumatol (United Kingdom) 58(11): 2051-2060.

63. Yurchenko E, Tritt M, Hay V, Shevach EM, Belkaid Y, et al. (2006) CCR5dependent homing of naturally occurring CD4+ regulatory $\mathrm{T}$ cells to sites of Leishmania major infection favors pathogen persistence. J Exp Med 203(11): 2451-2460.

64. Hirako IC, Ataide MA, Faustino L, Assis PA, Sorensen EW, et al. (2016) Splenic differentiation and emergence of $\mathrm{CCR}^{+}$CXCL9 $^{+} \mathrm{CXCL}^{+}{ }^{+}$ monocyte-derived dendritic cells in the brain during cerebral malaria. Nat Commun 7: 13277 
65. D’Adamo E, Cali AMG, Weiss R, Santoro N, Pierpont B, et al. (2010) Central role of fatty liver in the pathogenesis of insulin resistance in obese adolescents. Diabetes Care 33(8): 1817-1822.

66. Inayat H, Azim MK, Baloch AA (2019) Analysis of Inflammatory Gene Expression Profile of Peripheral Blood Leukocytes in Type 2 Diabetes. Immunol Invest 48(6): 618-631.

67. Słomiński B, Ławrynowicz U, Myśliwska J, Ryba-Stanisławowska M, Skrzypkowska M, et al. (2017) CCR5- $\Delta 32$ gene polymorphism is associated with retinopathy in patients with type 1 diabetes. Mol Cell Endocrinol 439: 256-260.

68. Carvalho-Pinto C, García MI, Gómez L, Ballesteros A, Zaballos A, et al. (2004) Leukocyte attraction through the CCR5 receptor controls progress from insulitis to diabetes in non-obese diabetic mice. Eur J Immunol 34(2): 548-557.

69. Kalev I, Oselin K, Pärlist P, Zilmer M, Rajasalu T, et al. (2003) CCchemokine receptor CCR5-del32 mutation as a modifying pathogenetic factor in type I diabetes. J Diabetes Complications 17(6): 387-391.

70. Buhler MM, Craig M, Donaghue KC, Badhwar P, Willis J, et al. (2002) CCR5 genotyping in an Australian and New Zealand type 1 diabetes cohort. Autoimmunity 35(7): 457-461.

71. Vassiliadis S, Balabanidou V, Papadopoulos GK, Athanassakis I (2002) Localization and expression of CCR3 and CCR5 by interleukin-1 $\beta$ in the RIN-5AH insulin-producing model system: A protective mechanism involving down-regulation of chemokine receptors. J Pancreas 3(3): 6675.
72. Muntinghe FLH, Gross S, Bakker SJL, Landman GWD, van der Harst $\mathrm{P}$ et al. (2009) CCR5 32 genotype is associated with outcome in type 2 diabetes mellitus. Diabetes Res Clin Pract 86(2): 140-145.

73. Hong YS, Chang Y, Ryu S, Cainzos-Achirica M, Kwon MJ, et al. (2017) Hepatitis $B$ and $C$ virus infection and diabetes mellitus: A cohort study. Sci Rep 7(1): 4606.

74. Dworzanski J, Drop B, Kliszczewska E, StrycharzDudziak M, PolzDacewicz M (2019) Prevalence of Epstein-Barr virus, human papillomavirus, cytomegalovirus and herpes simplex virus type 1 in patients with diabetes mellitus type 2 in south-eastern Poland. PLoS One 14(9): e0222607.

75. Heitner J, Dickson DW (1997) Diabetics do not have increased Alzheimer-type pathology compared with age-matched control subjects: A retrospective postmortem immunocytochemical and histofluorescent study. Neurology 49(5): 1306-1311.

76. Chornenkyy Y, Wang W-X, Wei A, Nelson PT (2019) Alzheimer's disease and Type 2 Diabetes mellitus are distinct diseases with potential overlapping metabolic dysfunction upstream of observed cognitive decline. Brain Pathol 29(1): 3-17.

77. Solloch U V, Lang K, Lange V, Böhme I, Schmidt AH (2017) Frequencies of gene variant CCR5- $\Delta 32$ in 87 countries based on next- generation sequencing of 1.3 million individuals sampled from 3 national DKMS donor centers. Hum Immunol 78(11-12): 710-717.

78. (2019) Global Health Data Exchange. 